\title{
On Constructivist Teaching Strategy of Landscape Architecture Design Liyuan $\mathrm{Li}^{1, \mathrm{a}}$ a and Yonggang $\mathrm{Xu}^{2, \mathrm{~b}}$ \\ ${ }^{1}$ School of Art and Design, Wuhan University of Science and Technology, China \\ ${ }^{2}$ College of Law \& Business, Hubei University of Economics, China \\ a181173081@qq.com, b568618159@qq.com
}

Keywords: Constructivist; Landscape architecture design; Teaching strategy; Education

\begin{abstract}
Based on Constructivist Teaching Theory, the paper puts forward three teaching strategies in the course of Landscape Architecture Design. Firstly, problem-solving-oriented teaching is helpful for students to investigate and research. Secondly, repositioning of teacher's role in class is good for students to construct their own knowledge and teacher should play as a guide and coordinator in the process. Thirdly, cooperative learning is contributive for students to display their initiative and thus develop their unique creativity. At the end of the paper, potential difficulties are also pointed out in teaching practice, such as students' inertia in study, negative impact of rigid mental set, and teacher' $s$ insufficient understanding of constructivist teaching methods.
\end{abstract}

\section{Constructivism and Constructivist Teaching Ideas}

Constructivism is a sub-branch of cognitive psychology, which is a result of the rising of Piaget's developmental stage theory and Vygotsky's Cognitive Developmental Theory, both of which are against behaviorist psychology. Piaget believed that one's childhood plays a vital and active role in a person's development. To Piaget, cognitive development was a progressive reorganization of mental processes resulting from biological maturation and environmental experience. He also believed that children construct an understanding of the world around them, experience discrepancies between what they already know and what they discover in their environment, and then adjust their ideas accordingly instead of accepting all the knowledge they receive without selection. [1]The major theme of Vygotsky's theoretical framework is that social interaction plays a fundamental role in the development of cognition. Vygotsky believed that every function in the child's cultural development appears first on the social level and later on the individual level, which applies equally to voluntary attention, to logical memory, and to the formation of concepts. All the higher functions originate as actual relationships between individuals. Vygotsky also held that the potential for cognitive development depends upon the "zone of proximal development" (ZPD): a level of development attained when children engage in social behavior. Full development of the ZPD depends upon full social interaction. The range of skill that can be developed with adult guidance or peer collaboration exceeds what can be attained alone. [2]

Constructivist learning theory holds that all knowledge is constructed from a base of prior knowledge. Children are not a blank slate and knowledge cannot be imparted without the child making sense of it according to his or her current conceptions. Therefore, children learn best when they are allowed to construct a personal understanding based on experiencing things and reflecting on those experiences.

Constructive teaching is based on constructivist learning theory and mainly be demonstrated from two perspectives. First, learning is a process of cognitive construction in which learners, with different backgrounds, from various angles and through their distinct information processing, shape their individual cognitive structure. That is to say, learners are actively involved in a process of constructing meaning and knowledge as opposed to passively receiving information. Learners are the makers of meaning and knowledge. Constructivists believe that learning is not a process of knowledge transmission from teacher to student but a process in which a learner actively construct his own knowledge structure. Instead of being a passive knowledge receiver, learners, with the help of the teachers and others, are actively involved in the construction of personal knowledge structure which 
can be only accomplished by learners themselves. Second, learners' cognitive structure, as a result of learning, is a network structure constructed around key concepts, which is different both from linear structure proposed by Gagne and from hierarchical structure proposed by Bruner and AuSubel. In the network structure all knowledge are closely-connected, which means that learners can start constructing from any node of the network and pick up knowledge without need to learn knowledge from the bottom of a linear or hierarchical structure.

Constructivism stresses the dynamism in the process of learning, active construction of learning process, and the sociality and contextuality of learning. These ideas are of great practical value and have urged educationists to start reforming traditional teaching model, which is also illuminative to the teaching practice of Landscape Architecture Design.

\section{Constructivist Teaching Strategies of Landscape Architecture Design}

Problem-Solving-Oriented Teaching Mode. Problem-solving-oriented teaching is helpful for students to investigate and research. In Problem-solving-oriented teaching, students are organized to investigate and study practical problems existing in landscape design, which is aimed to cultivate students' ability to understand, analyze and solve practical problems. In order to achieve this goal, a teacher has to take a lot of questions into account, including questions whether the problem proposed will successfully stimulate the students' curiosity to investigate afterwards, whether the problem proposed will provide sufficient opportunities so that the teaching goal can be attained, and whether the problem is helpful enough to lead student to independent self-study. [3]
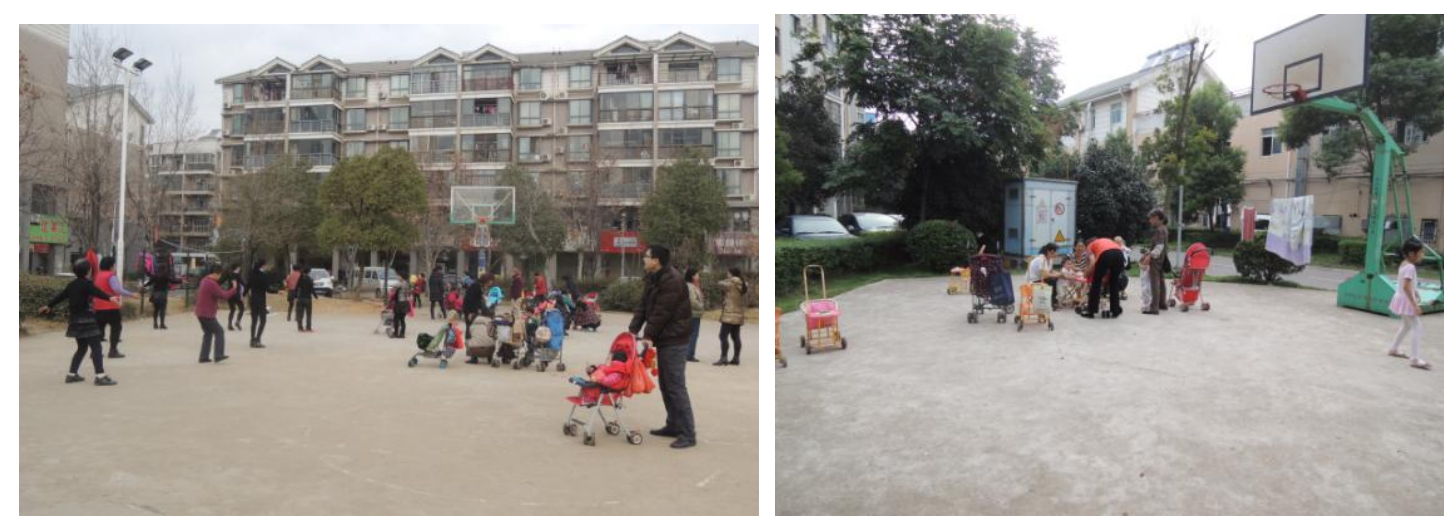

Figure 1. Problems existing in residential landscape

Take the following case as an example. In the class, a teacher first shows some pictures and videos about the activities of pre-school children in residential community and asks his student to find some problems existing in these activities (Fig. 1). After independent thinking and heated discussion, students point out the problem that the old baby-watchers has to bring small stools because of the lack of enough public bench for them to sit in, which brings a lot of inconveniencies for the old baby-watchers. Based on the problems pointed out by the students, the teacher should lead students to dealing another question what kind of residential landscape preschool children really need, which is to help students to develop problem-solving ability since pointing out problems alone is not sufficient enough for students to construct new knowledge.

The Repositioning of Teacher in the Class. The core value of constructivist teaching is to make students actively involved in the construction of new knowledge. However, it doesn't mean that students will construct new knowledge at their own will without any restriction. Instead, the teacher not only needs to stir up interests and motivations from his students but also has to guide them to use acquired knowledge to solve new problems so as to generate new knowledge. Accordingly, teacher should play a role of guide and coordinator when students are actively involved in the construction of new knowledge. The main task of a teacher is to design a learning context suitable for students so that they can discover new knowledge and construct new concepts through connection, comparison and 
analysis, which are very helpful for students to develop their self-study ability. Also, in the process of constructivist teaching, the teacher should help students to master some effective and efficient learning methods to acquire new knowledge so that they can construct it smoothly and successfully.

In the previous case, when the teacher asks students to deal with the question how to solve the existing problems, he should, at the same time, provide some methods for students to attain the solution.

The first and foremost is field research. The students can choose 3 to 5 residential communities to start field research, from which students will have a direct contact with the existing problems by means of direct observation or informal interviews. Field studies are one of the most valuable methods for setting a design project's direction and discovering unmet user needs. But studying and questioning users does no good if you tell them the answers--because then you won't truly learn anything new.

The second is literature survey. Students can start their project through searching online and offline sources to find related information by inputting some key words such as the demand of children, the characteristics of children's behavior, outdoor environment of residential community. Also, the teacher is recommended to support the students with some successful cases on which the students can analyze how these fine landscape designs of residential communities from overseas and homeland successfully satisfy the demand of pre-school children for outdoor environment of residential community. Literature survey can help students overcome the temporal, regional and quantitative restriction and allow students a good chance to closely examine a great number of excellent landscape designs that is hard, if not impossible, to be studied by students otherwise.

Construction of New Knowledge through Cooperative Learning. Compared with traditional teaching mode in class, the teaching mode based on constructivism is equipped with new characteristics such as interactivity, automaticity, and etc. A case in point is MOOC, which is not limited by time and space. On the one hand, students are allowed to study on their individual schedule.[4] On the other hand, students is forced to complete assignments, deliberations, quizzes and tests if they want to acquire corresponding certificate. Assignment is usually evaluated by peer-students and every student is required to assess at least 6 times. Deliberation is usually conducted in corresponding discussion room and every student is required to express his own idea about the related topics.

The class teaching of Landscape Architecture Design can also adopt similar methods. Students can be divided into several groups, each of which contains 3 to 5 members. The members of each group should cooperate with each other in order to complete the assignment given by the teacher, and then discuss and evaluate assignments proposed by other groups. At the end of the class activity, the teacher will give suggestions and guidance for students.

\section{The Difficulties in Constructivist Teaching of Landscape Architecture Design}

Although constructivist teaching of Landscape Architecture Design does attain some effective results in experimental environment, it still faces a lot of difficulties in class teaching.

The first one is that students lack initiative. Constructivist teaching emphasizes learners' active construction of knowledge, which means that students are the center in the process of constructing knowledge. However, deeply influenced by the culture of exam-oriented education, Chinese students usually lack the initiative and interest to start their own study, and thus in constructivist teaching they are usually pushed by the teacher to finish their task, which is obviously against the original purpose of constructivist education.

The second one is that most students have developed a rigid mental set. In constructivist teaching, students are required of critical thinking, systematic thinking and divergent thinking. However, students, in deep culture of exam-oriented education, have been used to accepting cramming teaching and memorizing book knowledge without much understanding. As a result, students are really bad at finding questions and solving problems, which are essential components in constructivist teaching. 
The third one is that teachers don't properly understand the methods of constructivist teaching. Constructivist teaching poses higher demand for teachers. Teachers should not only be a knowledge-transporter, but a partner and guide for students to construct knowledge. Teacher should not only be good at professional knowledge, but also be equipped with methods of constructivist teaching, for example, anchored instruction, scaffolding instruction, random access instruction, and etc. The current situation is not promising since a lot of teachers have a poor command of these methods. Although most of college teachers are doctors, they are rarely equipped with knowledge related with Pedagogy and psychology. If they do not receive proper instruction and training related with these subjects, teacher will not be able to effectively help students construct their own knowledge. [5]

\section{Conclusion}

Constructivism poses a great challenge to traditional class teaching and some constructivist ideas are quite helpful for students' self-improvement. Therefore, it is necessary to introduce constructivist teaching methods into the teaching of Landscape Architecture Design and related disciplines, which will exert an important, positive and realistic influence on the reform in education and teaching.

\section{Acknowledgements}

Financial support for this work, provided by:

1. Teaching Research Program, Wuhan University of Science and Technology, NO2015X057;

2. Provincial Teaching Research Project of Colleges and Universities in Hubei, NO2012225.

\section{References}

[1] McLeod, S. A. (2015). Jean Piaget. Retrieved from www.simplypsychology.org/piaget.html

[2] Information on http://www.instructionaldesign.org/theories/social-development.html

[3] W. Gao, B.Y. Xu and G. Wu: On Constructivist Teaching (Educational Science Publishing House, China, 2008) (In Chinese).

[4] B.L. Huang: Art Education Research, Vol. 5 (2014) No.17, p.128-129(In Chinese).

[5] M.C. Zhao: Journal of Higher Education, Vol. 23 (2002) No.3, p.73-77(In Chinese).

[6] K.K.He: Journal of Beijing Normal University (Social Science Edition), Vol.42 (1997) No.5, p.74-81(In Chinese).

[7] W.Fu and S.L.Zhao: Journal of the Chinese Society of Education, Vol.35 (2014) No.5, p.72-76(In Chinese).

[8] Y.Zou: Foreign Language Research, Vol.32 (2009) No.5, p.117-120(In Chinese).

[9] Q.W.Li and J.Voneche: Journal of East China Normal University (Humanities and Social Sciences), Vol.32 (2000) No.5, p.3-10(In Chinese).

[10]G.R.Wang: Journal of Central China Normal University (Humanities and Social Sciences), Vol.53 (2014) No.5, p.164-169(In Chinese). 